\title{
Intraosseous composite hemangioendothelioma of the mandible: case report and literature review
}

\author{
Ting Mao ${ }^{1}$, Haofeng Xiong ${ }^{2}, \mathrm{Ning}^{\mathrm{Li}^{1}}$, Tong Su${ }^{1}$ \\ ${ }^{1}$ Centre of Stomatology, Xiangya Hospital, Central South University, Changsha 410008, China; ${ }^{2}$ Center for Medical Genetics, School of Life \\ Sciences, Central South University, Changsha 410008, China \\ Contributions: Tong Su, MD. Centre of Stomatology, Xiangya Hospital, Central South University, NO.87 Xiangya Road, Changsha 410008, China. \\ Email: sutongs@csu.edu.cn.
}

\begin{abstract}
Composite hemangioendothelioma (CHE) is a locally aggressive intermediate malignant vascular tumor characterized by a mixture of histologic patterns. CHE is considered to be an intermediate malignant tumor, which mainly occurs in the dermis and subcutaneous lesions of the limbs, and may grow and invade nearby bones. CHE occurs in the mandible are rare, especially in its ramus. Because of its rarity, in the mandible, CHE must not only be distinguished from other vascular tumors that can arise in this location, capillary hemangioma and, but also from other mandibular tumors, such as ameloblastoma, which may cause inadequate resection of the lesion and recurrence of the tumor. We summarize the previous CHE cases and conclude the differences and similarities between the characteristics of $\mathrm{CHE}$ in other parts and $\mathrm{CHE}$ in oral cavity. And microscopically, CHE in this case consist with three different pathological features: spindle-cell hemangioma-like areas, retiform hemangioendothelioma-like areas and epithelioid hemangioendotheliomalike areas. Immunohistochemically, the tumor cells were positive for CD34, CD31, FLI-1 and D2-40. The expression of KI67 reached 50\% in some regions and less than $10 \%$ in some regions, respectively. No recurrent disease was noted 40 months after the surgery. Therefore, we report a rare case of tumor in the mandibular ramus to increase the clinician's understanding of the maxillofacial CHE.
\end{abstract}

Keywords: Composite hemangioendothelioma (CHE); hemangioendothelioma; mandible; vascular tumour; immunohistochemistry; imaging findings

Received: 08 October 2019; Accepted: 02 April 2020; Published: 15 May 2020.

doi: $10.21037 /$ fomm.2020.04.01

View this article at: http://dx.doi.org/10.21037/fomm.2020.04.01

\section{Introduction}

According to the ISSVA classification for vascular anomalies (2018), composite hemangioendothelioma (CHE) is defined as locally aggressive or borderline vascular tumors. Vascular tumors can be divided into three categories according to the degree of malignancy: benign tumors, locally aggressive or borderline tumors, malignant tumors. Locally aggressive or borderline tumors. Locally aggressive or borderline vascular tumors is a low-grade malignant tumor with metastatic potential which includes: kaposiform hemangioendothelioma, retiform hemangioendothelioma (RHE), papillary intralymphatic angioendothelioma, Dabska tumor, CHE, pseudomyogenic hemangioendothelioma, polymorphous hemangioendothelioma, hemangioendothelioma not otherwise specified Kaposi sarcoma, and others (1).

Through the analysis of the existing literature reports, CHE mainly occurs in the dermis and subcutis of extremities, but rarely in bones (2). And it mainly occurs in young and middle-aged women, with a long course of illness and painless growth of tumors. It is easy to recur after surgical excision, but less metastasis occurs (3). Due to the rarity of $\mathrm{CHE}$, it is difficult for general clinicians in maxillofacial surgery and pathology to diagnose the disease accurately, which leads to the inaccurate statistics of its incidence. Fifty-six cases of CHE have been reported in English literature since the definition of CHE was made 

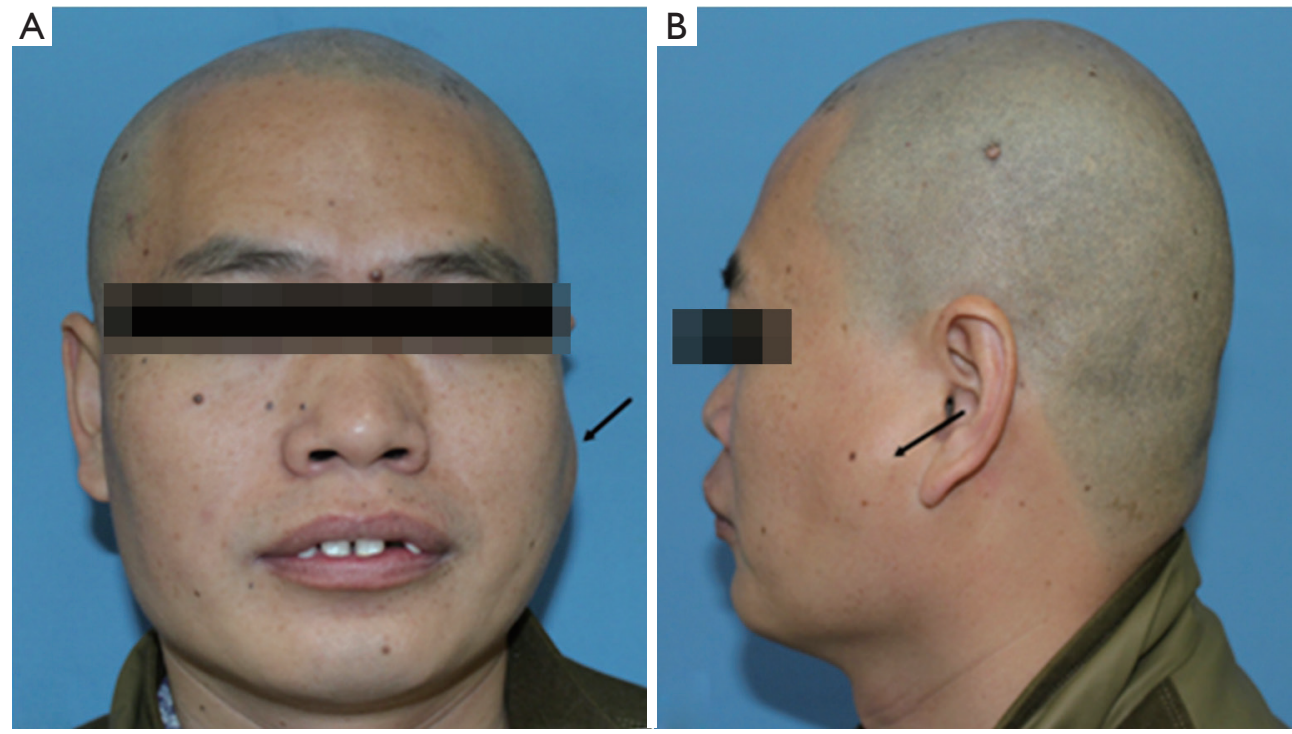

Figure 1 Facial expression of the patient before surgery: Where the arrow points, a round mass of quail egg size can be seen at about 2 cm before the external auditory canal. It is characterized by tenacity and no obvious activity (Announced after patient consent).

clear in 2000.

As far as we know, CHE originating in the mandible ramus hasn't been reported in the English literature before. In the present paper, we report a case of CHE in the ramus of mandible.

\section{Case presentation}

A 36-year-old male patient was admitted to our hospital due to a mass grown on his left mandible ramus for approximately 10 months (Figure 1). The patient did not mention any noticeable symptoms related to the tumor. $\mathrm{He}$ had no personal or family history of significant diseases. On palpation, no lymph nodes of the neck region were palpable.

Through computed tomography and cone beam computed tomography, the cortex of the left mandibular body was eroded. In addition, the condyle contained a mass with an abnormal signal but mostly well-defined borders (Figure 2). The lesion was $31 \mathrm{~mm} \times 26 \mathrm{~mm}$ with high density in the center and an arc shape in the border with heterogeneously increased density which suggests osteolytic changes. No reactive hyperplasia was observed in the surrounding bone.

Magnetic resonance imaging (MRI) of the oral and maxillofacial region revealed an abnormal high signal intensity on a T2-weighted image beside the mandibular body with low signal intensity in the center of the lesion.
The area also showed high signal intensity on enhanced T1-weighted MR images. The demarcation of the lesion was unclear (Figure 3). The lesion extensively occupied the left ramus of the mandibular body, causing displacement of the left masseter.

Based on the clinical findings and the imaging report, a biopsy was performed. Microscopically, we found three regions with different pathological features. Spindle-cell hemangioma-like areas (SHE-like areas): capillary dilatation was obvious, vascular endothelial cells were flat and spindleshaped. Retiform hemangioendothelioma-like areas: The neoplasm is composed of elongated arborizing vessels arranged in anastomosing pattern, at high magnification, the tumor cells can be seen with abundant pale eosinophilic cytoplasm, vesicular nuclei and inconspicuous nucleoli. Many tumor cells show obvious cytoplasmic vacuolation, which is characterized by the expression and differentiation of primitive blood vessels, similar to the changes of epithelioid cells (Figure 4).

Immunohistochemical stains of tumor cells were positive for CD31, CD34, and FLI-1 with scattered D2-40 positive foci (Figure 5), supporting a neoplasm of vascular origin. The expression of KI67 reached $50 \%$ in some regions and less than $10 \%$ in some regions. On the whole, Ki-67 immunostain revealed a $15 \%$ proliferative rate consistent with a tumor of malignant potential.

In view of the above characteristics, The final diagnosis is 

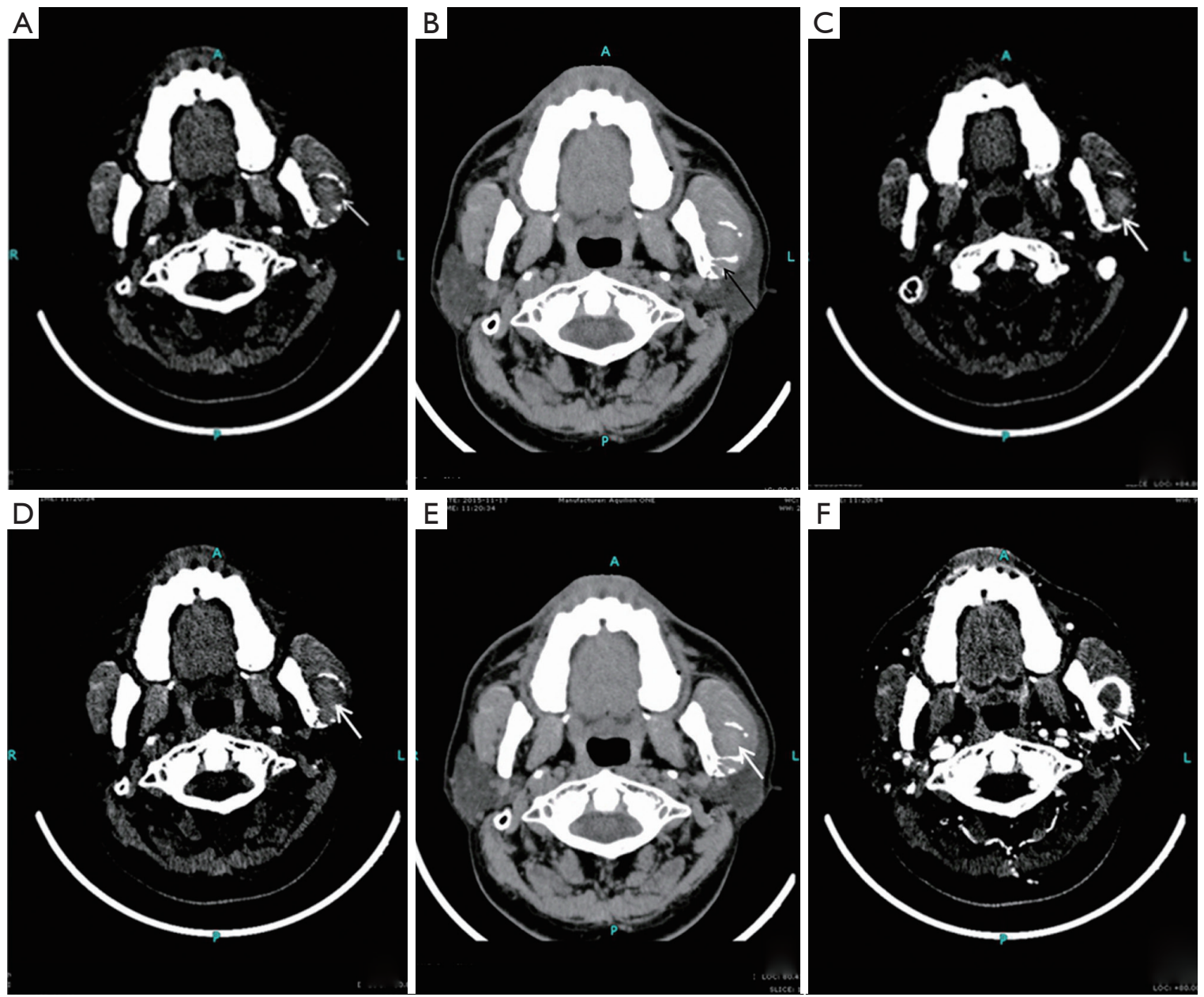

Figure 2 Computed tomography of the lesion in the left ramus of the mandible: the mass was located in the ascending ramus of the mandible and its boundary was unclear. It invaded the condyle. Bone was absorbed by compression and displaced to the depth of masseter muscle. Bone in sigmoid notch also expanded upward.

suggested tend to be CHE, which consists of SHE-like areas, RHE-like areas and epithelioid hemangioendothelioma-like areas (EHE-like areas). Thus, an extended local resection of the neoplasm in the left mandibular body and reconstruction using a vascularised ilium flap was performed. We followed up the patient for nearly 40 months and the patient did not relapse so far (Figure 6).

\section{Discussion}

In 1908, Mallory used the term hemangioendothelioma to include all proliferations that he believes to be the origin of vascular endothelial cells. Nowadays, $\mathrm{HE}$ is used to name those vascular neoplasms that show a borderline biological behavior. CHE is an uncommon vascular tumor which was first described in 2000 by Nayler et al., and 8 cases of a vascular tumour with varying combinations of benign, lowgrade malignant, and malignant vascular components was reported (4).

After reviewing articles retrieved by search from PubMed up to march 2019, it seems that CHE is really rare and only 56 cases have been reported in the literature so far. According to the statistics of Stojsic et al. in 2014, 23 cases of cutaneous CHE from 2000 to 2014 (5). In 2017, Perry et al. had reported 11 cases (6). To supplement the data, we describe the remaining 22 cases in detail in the Table 1 and Table 2 (2,3,7-23). Whatever, there is no doubt that true incidence of these tumors has been underestimated.

In the above cases, we conclude that CHE mainly occurs in the dermis and subcutaneous lesions of the limbs, and 

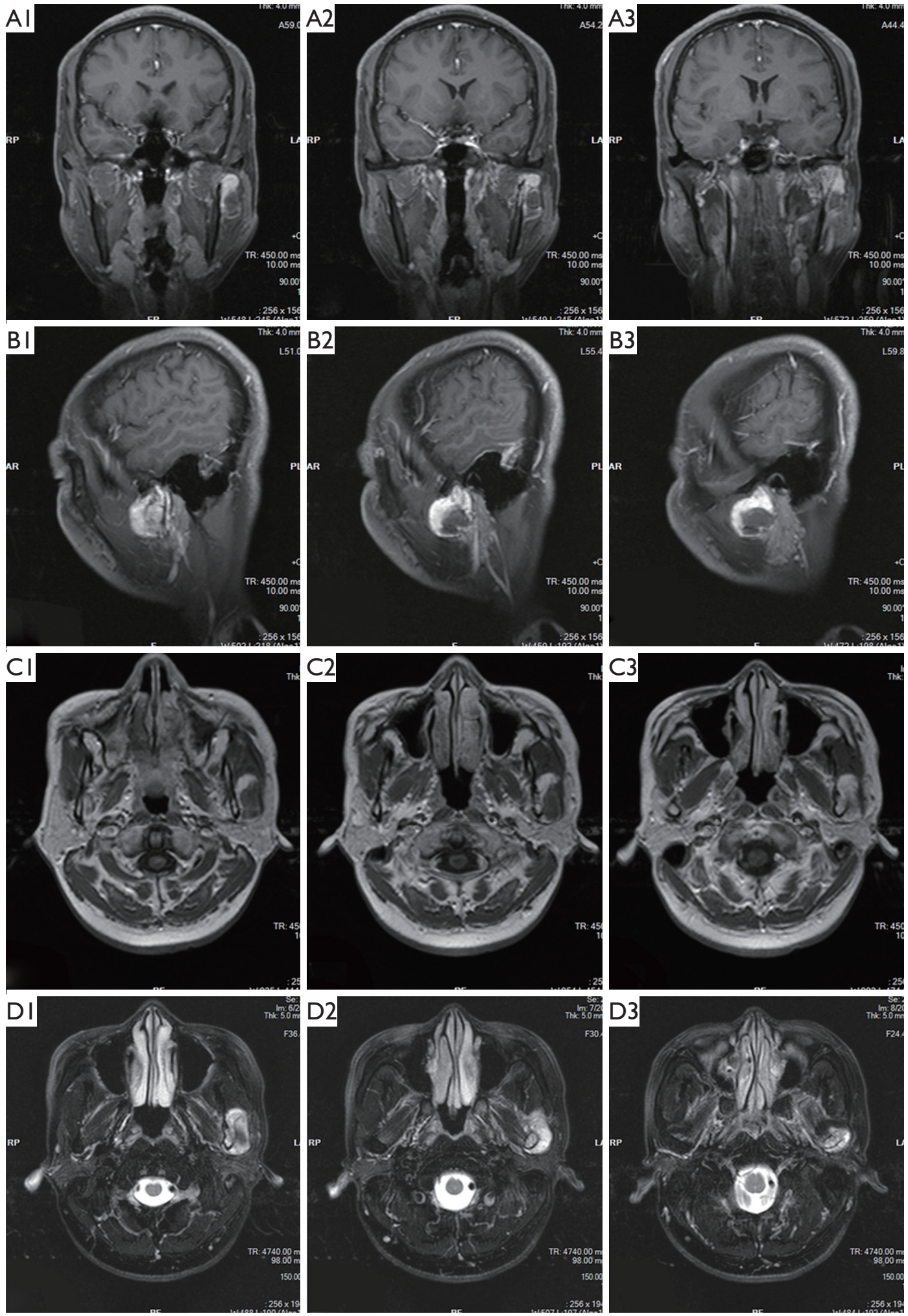

Figure 3 Magnetic resonance imaging of the neoplasm: in the pictures of A, B, C, group shows the tumor position of coronal section, median sagittal section, transverse section; it shows inhomogeneous T1 high signal intensity of the mass, the left condyle was involved in A3; the D group showed the tumor on T2 weighted images showed high signal intensity. 


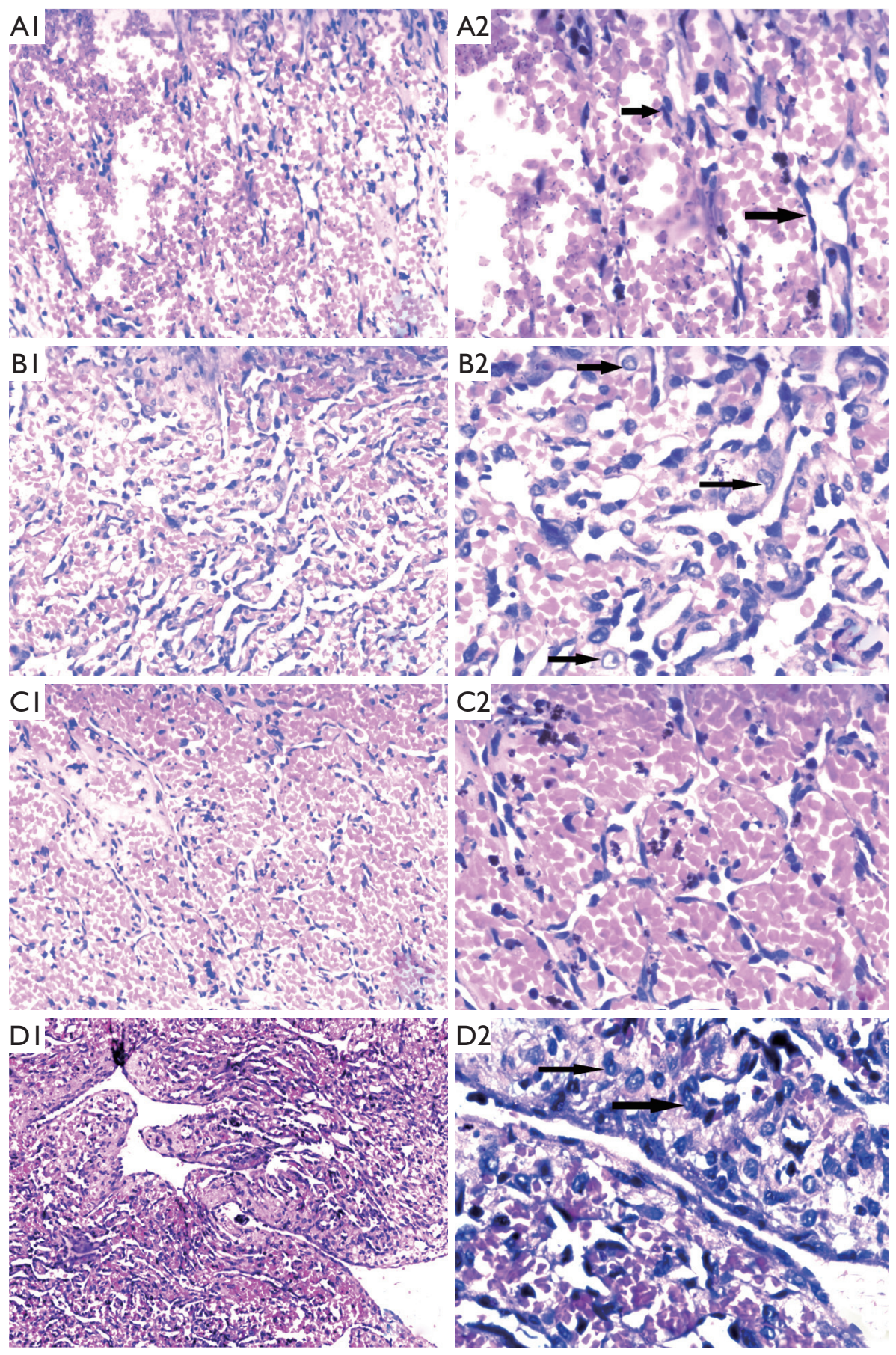

Figure 4 Pathological structure of tumor tissue: on the left is the low power field $(\mathrm{H} \& \mathrm{E}: \times 100)$, the right list shows the high power field (H\&E: $\times 400)$; (A1, A2) Spindle-cell hemangioma-like areas: Capillary dilatation was obvious, vascular endothelial cells were flat and spindle-shaped. (B1, B2) Retiform hemangioendothelioma-like areas: The neoplasm is composed of elongated arborizing vessels arranged in anastomosing pattern, at high magnification, the tumor cells can be seen with abundant pale eosinophilic cytoplasm, vesicular nuclei and inconspicuous nucleoli. Tumor cells shown by arrows exhibit marked cytoplasmic vacuolar degeneration, showing the expression and differentiation of primitive blood vessels, similar to changes in epithelioid cells. (C1, C2) The dilated capillaries are filled with mature red blood cells, and the vascular endothelial cells in the wall of the capillaries are evident. (D1, D2) The vascular structures are lined by some endothelial cells. 

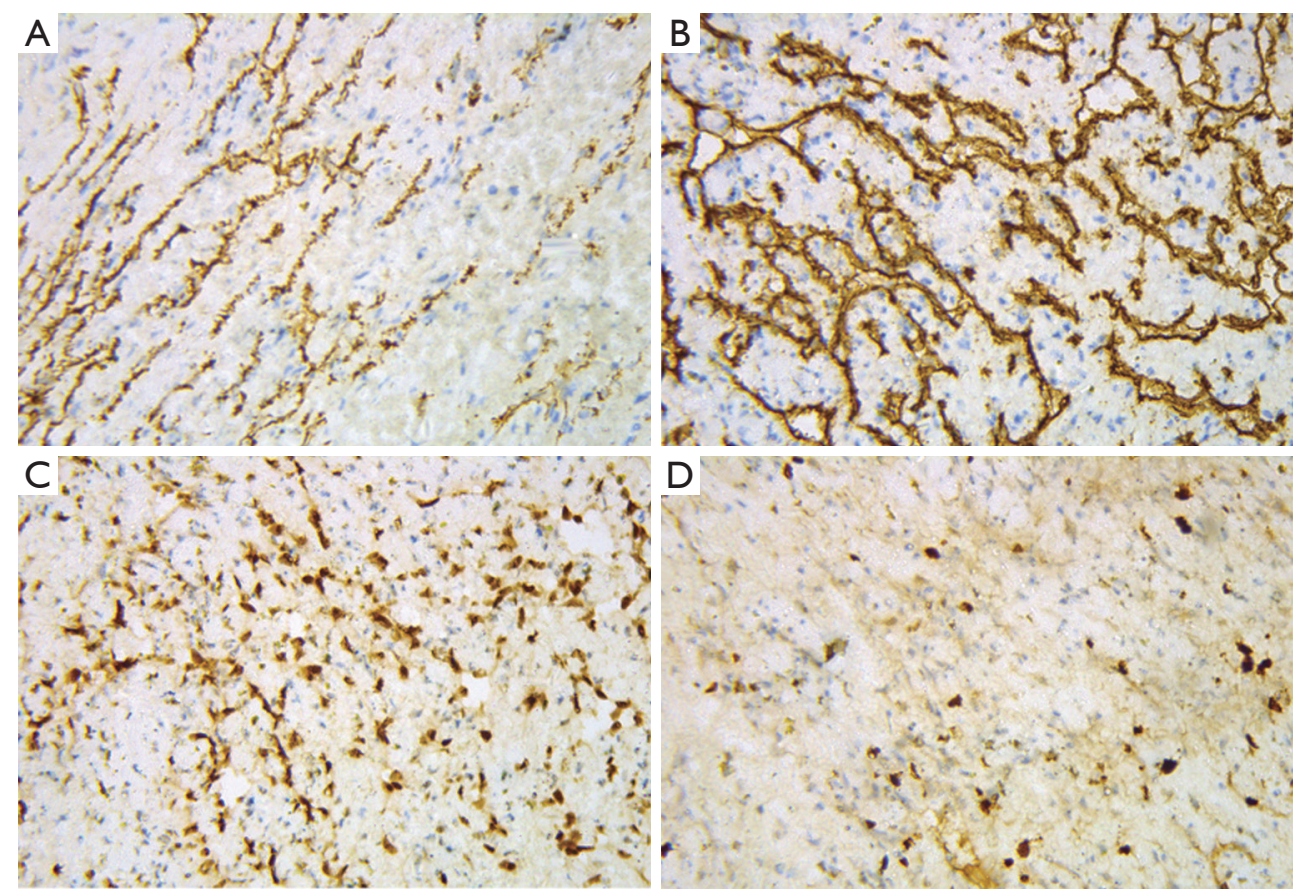

Figure 5 Immunohistochemical findings (×100): (A) CD31 (positive); (B) CD34 (strongly positive); (C) FLI-1 (positive); (D) KI-67 (15\%).
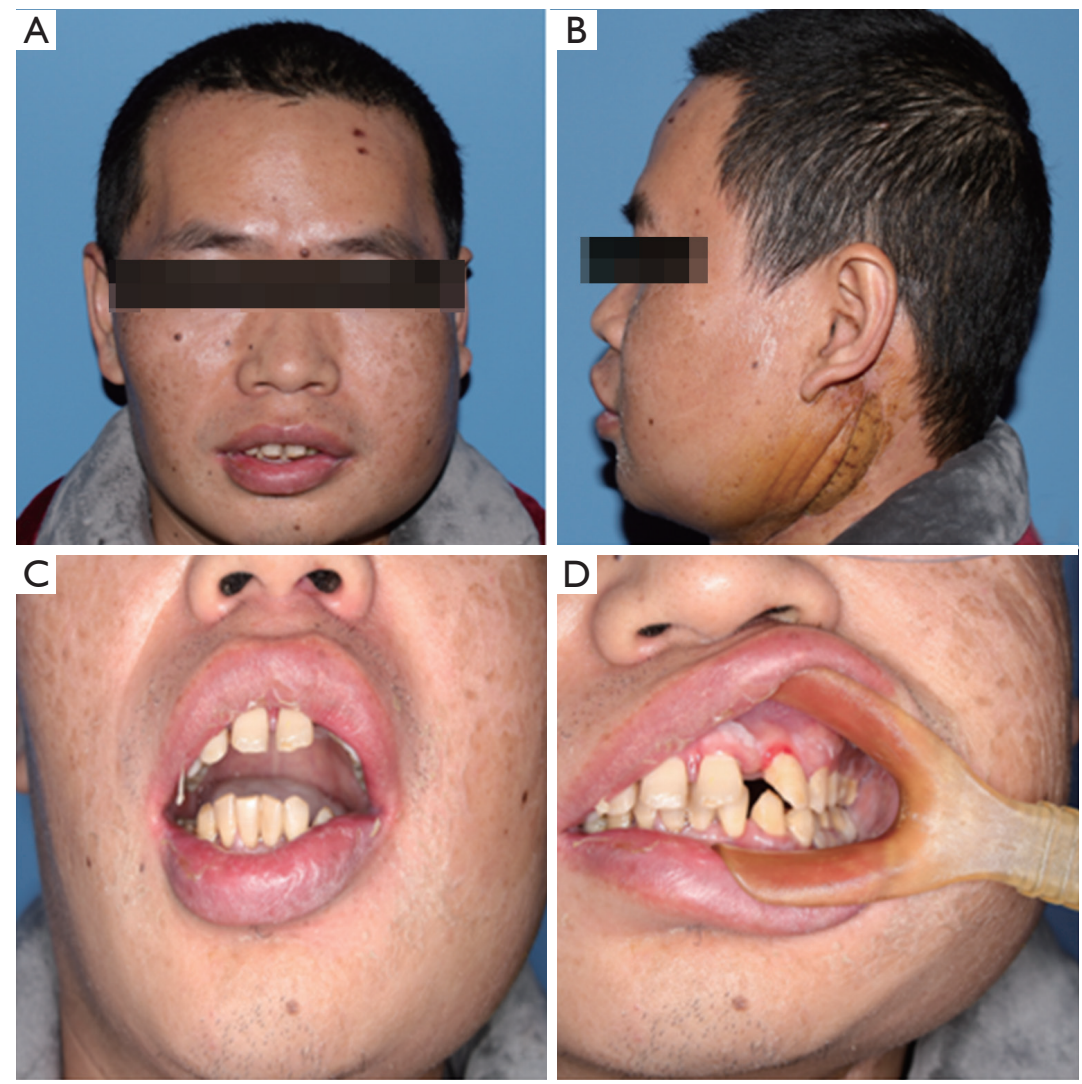

Figure 6 Follow up: the patient had well facial appearance with recovered occlusion and normal functions of feeding and speech. 


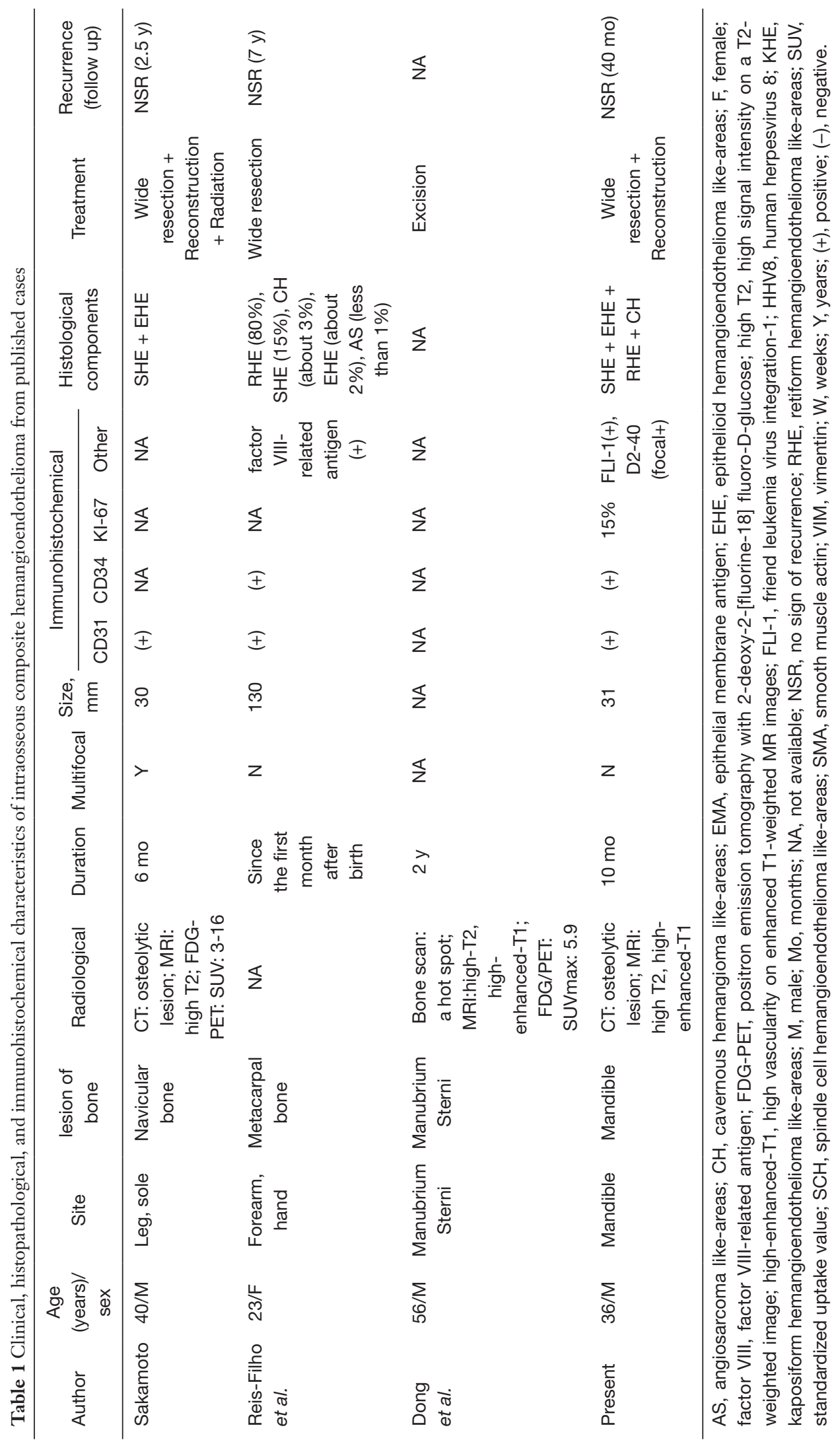




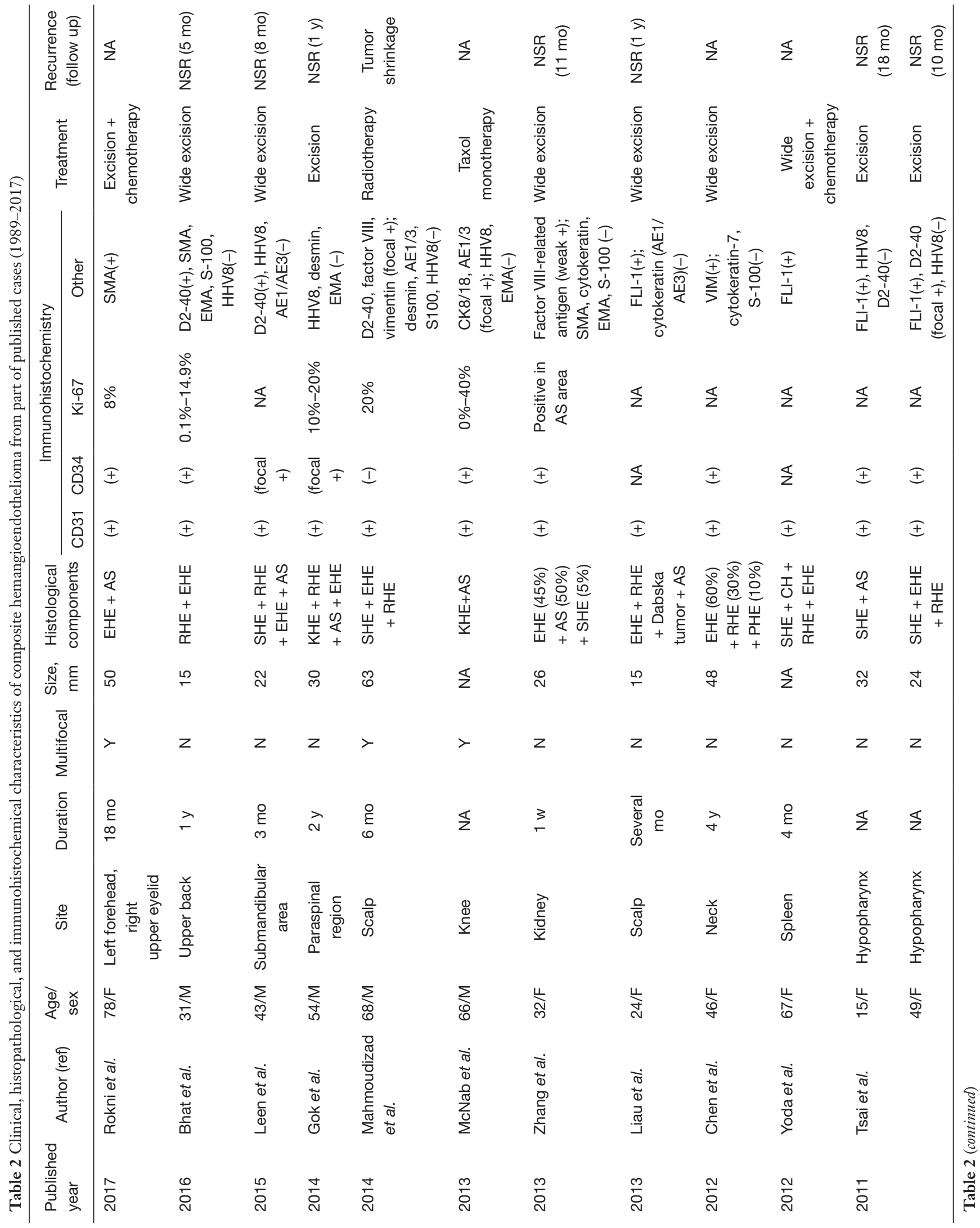




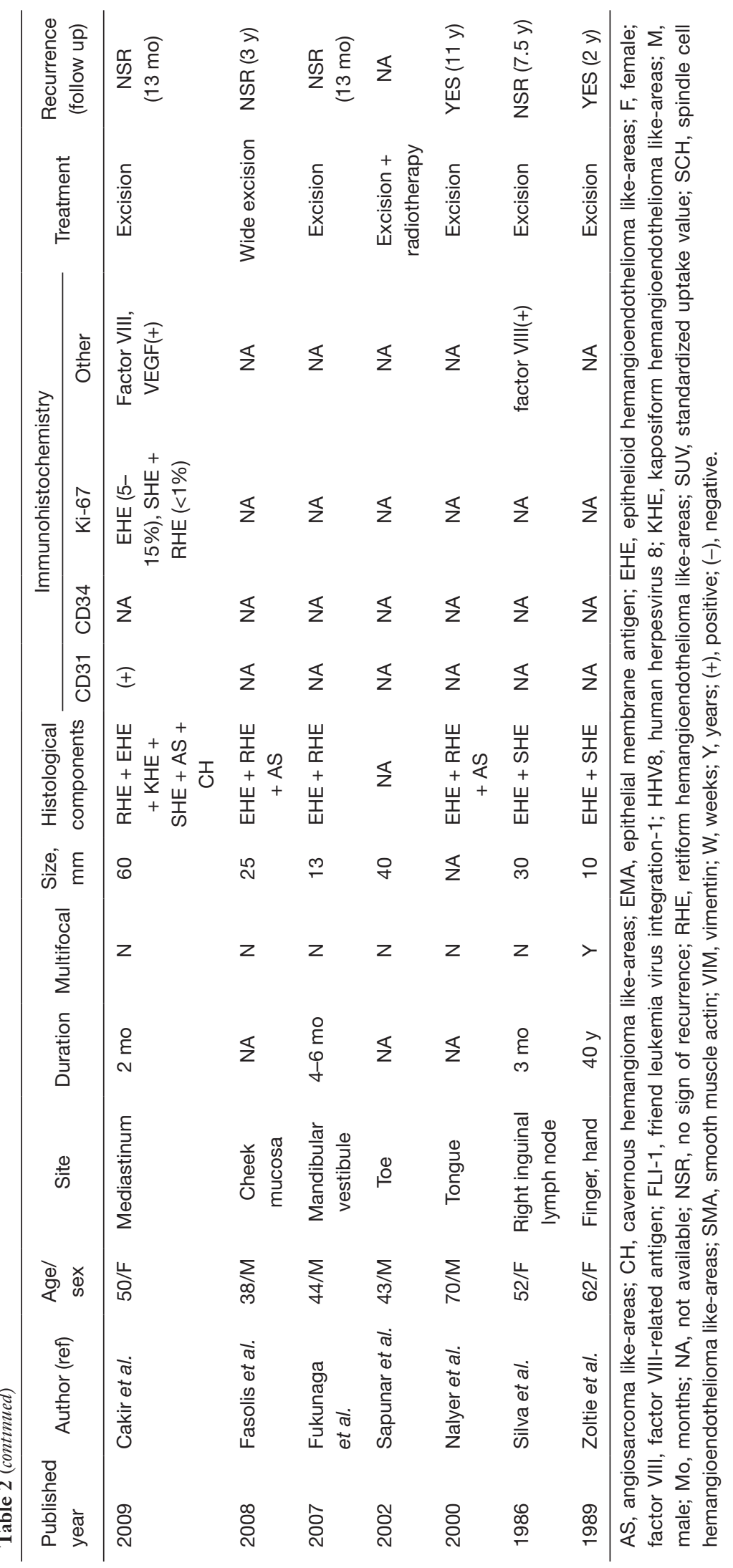


may grow and invade nearby bones. However, more and more reports have been made on other parts, including the oral cavity and kidneys and other internal organs, especially in the head and neck $(4,14,16,17,20,21)$. CHE has a wide range of age of onset and a slight female preponderance (32/56). Since the majority of tumors show painless growth, most patients have relatively long tumor durations. From the previous cases, it was found that the tumor could be single or multiple lesions, ranging in size from 0.7 to $30 \mathrm{~cm}$. It has a propensity to recur locally and the ability to metastasize. We have follow-up data of 40 cases after resection, with a local recurrence rate of $25 \%(10 / 40)$ and a latency of 4-10 years. A study in 2017 showed that CHE with neuroendocrine differentiation often involved deeper areas and exhibited more aggressive behavior than other cases of CHE (6). Because of its rarity, the best treatment for CHE is still controversial, but generally associated with local resection and surgical treatment, it has been shown that extensive resection may be due to the propensity for local recurrence, and is recommended with computed tomography or magnetic resonance imaging to follow regional lymph node evaluation. Adjuvant chemoradiotherapy should also be considered if necessary, electron beam therapy has also been used to treat a composite $\mathrm{HE}$ of the nose (24). CHE is characterized by a combination of benign and malignant vascular proliferations. The prognosis of CHE depends on the single components and is therefore varying. Thus, it's meaningful to specify the components of $\mathrm{CHE}$ and their proportions. The most common combination of components is RHE and EHE. Angiosarcoma-like areas are present in around half of CHE, and may be proportionally more common in congenital or childhood cases. However, the most common manifestation of angiosarcoma is painful injury, which easily invades adjacent soft tissues and nerves, so that it can be differentiated and diagnosed.

Immunohistochemically, tumor vascular endothelial markers CD31, CD34, von Willebrand factor (vWF), factor-VIII-related antigen were variably or focally expressed, while D2-40 was rarely expressed. HHV8, cell keratin, epithelial membrane antigen, $\mathrm{S} 100$ protein, desmin and smooth muscle actin is always negative in CHE. The Ki67 proliferation index is variable and generally low (less than $1 \%$ in RHE-like and SH-like areas, Less than 5-15\% in the EHE-like areas), but higher locally (up to 50\%) in the angiosarcoma-like areas.

From Table 1, it can be concluded that lesions of CHE shows osteolytic changes in computed tomography. On magnetic resonance imaging, the mass always showed heterogeneous signal hyperintensity along the external surface of the mandibular cortical plate on T2-weighted imaging. In our case, there are some certain extraordinary radiographic imaging in the lesion such as osteolytic changes, hardened border and internal bone crest (Figure 2). $18 \mathrm{~F}$-fluorodeoxyglucose positron emission tomographycomputed tomography (FDG-PET/CT) findings in CHE also lead a diagnosis, in the case of manubrium sterni, the high 18F-fluorodeoxyglucose uptake of tumor indicated its malignant potential (9).

Overall, Primary CHE in the bone is rare and there are only three cases has been reported. Two of them originating from skin of the extremities, and then invade nearby bones (8). Just one of them primary in the manubrium sterni (9). About the etiology of $\mathrm{CHE}$, one theory is that CHE is often associated with underlying vascular abnormalities, and histologically often contain benign vascular components (25). As we know, hemangiomas are one kind of vascular abnormalities which rarely primary in bones. And comparing with long bone, hemangiomas occur more in the flat bone. Interestingly, previous scholars believe that $\mathrm{CHE}$ is more common in the long tubular bone. And our case also proves that (Table 1).

Due to the malignant nature of the tumor, it is easy to be too conservative to cause local recurrence, or too aggressive, causing unnecessary damage to sacrifice quality of life. With this case report and those in the literature, we hope to increase our knowledge of $\mathrm{CHE}$ and improve clinical diagnosis of similar case.

\section{Acknowledgments}

The author is grateful for research support from Professor Hongling Yin, the Department of Pathology, Xiangya Hospital and Professor Zhigang Yao, the Department of Oral Pathology, Xiangya Stomatological Hospital, Central South University (CSU), China.

Funding: This work was supported by the National Natural Science Foundation (81873717); and the Natural Science Foundation of Hunan Province (2019JJ40508); and the Graduate Students Independently Explore Innovative Projects of Central South University (2019zzts787), China.

\section{Footnote}

Conflicts of Interest: All authors have completed the ICMJE uniform disclosure form (available at https://fomm. 
amegroups.com/article/view/10.21037/fomm.2020.04.01/ coif). The authors have no conflicts of interest to declare.

Ethical Statement: The authors are accountable for all aspects of the work in ensuring that questions related to the accuracy or integrity of any part of the work are appropriately investigated and resolved. All procedures performed in studies involving human participants were in accordance with the Declaration of Helsinki (as revised in 2013). Approved by the Medical Ethics Committee of Xiangya Hospital, Central South University. The patient's permission for publication was obtained.

Open Access Statement: This is an Open Access article distributed in accordance with the Creative Commons Attribution-NonCommercial-NoDerivs 4.0 International License (CC BY-NC-ND 4.0), which permits the noncommercial replication and distribution of the article with the strict proviso that no changes or edits are made and the original work is properly cited (including links to both the formal publication through the relevant DOI and the license). See: https://creativecommons.org/licenses/by-nc-nd/4.0/.

\section{References}

1. Steele L, Zbeidy S, Thomson J, et al. How is the term haemangioma used in the literature? An evaluation against the revised ISSVA classification. Pediatr Dermatol 2019;36:628-33.

2. Bhat A, Chowdappa V. Composite Hemangioendothelioma: Report of a Rare Case. J Clin Diagn Res 2016;10:ED01ED03.

3. Leen SL, Clarke PM, Chapman J, et al. Composite Hemangioendothelioma of the Submandibular Region. Head Neck Pathol 2015;9:519-24.

4. Nayler SJ, Rubin BP, Calonje E, et al. Composite hemangioendothelioma: a complex, low-grade vascular lesion mimicking angiosarcoma. Am J Surg Pathol 2000;24:352-61.

5. Stojsic Z, Brasanac D, Stojanovic M, et al. Cutaneous composite hemangioendothelioma: case report and review of published reports. Ann Saudi Med 2014;34:182-8.

6. Perry KD, Al-Lbraheemi A, Rubin BP, et al. Composite hemangioendothelioma with neuroendocrine marker expression: an aggressive variant. Mod Pathol 2017;30:1589-602.

7. Sakamoto A. Reconstruction With beta-Tricalcium Phosphate After Navicular Tumor Resection. J Foot Ankle
Surg 2017;56:98-102.

8. Reis-Filho JS, Paiva ME, Lopes JM. Congenital composite hemangioendothelioma: case report and reappraisal of the hemangioendothelioma spectrum. J Cutan Pathol 2002;29:226-31.

9. Dong A, Bai Y, Wang Y, et al. Bone scan, MRI, and FDG PET/CT findings in composite hemangioendothelioma of the manubrium sterni. Clin Nucl Med 2014;39:e180-3.

10. Rokni GR, Montazer F, Sharifian M, et al. Composite hemangioendothelioma of the forehead and right eye; a case report. BMC Dermatol 2017;17:15.

11. Gok S, Berkman MZ, Baykara E. Composite Hemangioendothelioma Settled in the Paraspinal Region: A Rare Case Report. Turk Neurosurg 2020;30:299-302.

12. Mahmoudizad R, Samrao A, Bentow JJ, et al. Composite hemangioendothelioma: An unusual presentation of a rare vascular tumor. Am J Clin Pathol 2014;141:732-6.

13. McNab PM, Quigley BC, Glass LF, et al. Composite hemangioendothelioma and its classification as a low-grade malignancy. Am J Dermatopathol 2013;35:517-22.

14. Zhang J, Wu B, Zhou GQ, et al. Composite hemangioendothelioma arising from the kidney: case report with review of the literature. Int J Clin Exp Pathol 2013;6:1935-41.

15. Liau JY, Lee FY, Chiu CS, et al. Composite hemangioendothelioma presenting as a scalp nodule with alopecia. J Am Acad Dermatol 2013;69:e98-9.

16. Chen YL, Chen WX, Wang J, et al. Composite hemangioendothelioma on the neck. Kaohsiung J Med Sci 2012;28:564-5.

17. Yoda Y, Ohashi M. A case of composite hemangioendothelioma arising from the spleen. Jpn J Clin Oncol 2012;42:770.

18. Tsai JW, Huang HY, Lee JC, et al. Composite haemangioendothelioma: report of four cases with emphasis on atypical clinical presentation. Pathology 2011;43:176-80.

19. Cakir E, Demirag F, Gulhan E, et al. Mediastinal composite hemangioendothelioma. A rare tumor at an unusual location. Tumori 2009;95:98-100.

20. Fasolis M, Iaquinta C, Montesco MC, et al. Composite hemangioendothelioma of the oral cavity: case report and review of the literature. Head Neck 2008;30:974-9.

21. Fukunaga M, Suzuki K, Saegusa N, et al. Composite hemangioendothelioma: report of 5 cases including one with associated Maffucci syndrome. Am J Surg Pathol 2007;31:1567-72.

22. Sapunar J, Roa JC, Moscoso S. [Reversion of 
hypophosphatemia after the excision of a composite hemangioendothelioma in the great toe]. Rev Med Chil 2003;131:909-14.

23. Zoltie N, Roberts PF. Spindle cell haemangioendothelioma in association with epithelioid haemangioendothelioma. Histopathology 1989;15:544-6.

\section{doi: $10.21037 /$ fomm.2020.04.01}

Cite this article as: Mao T, Xiong $\mathrm{H}, \mathrm{Li} \mathrm{N}, \mathrm{Su}$ T. Intraosseous composite hemangioendothelioma of the mandible: case report and literature review. Front Oral Maxillofac Med 2020;2:7.
24. Tateishi J, Saeki H, Ito K, et al. Cutaneous composite hemangioendothelioma on the nose treated with electron beam. Int J Dermatol 2013;52:1618-9.

25. Shang Leen SL, Fisher C, Thway K. Composite hemangioendothelioma: clinical and histologic features of an enigmatic entity. Adv Anat Pathol 2015;22:254-9. 